The favorable influence of the oiled gauze is explained by the protection that the oil furnishes against swelling of the thread and obstruction of the mesh.

I have not yet had the opportunity of investigating whether it is as little adhesive as the Fisher preparations; but it is certainly more favorable to absorption, and I would therefore suggest its use for dressing moist wounds.

\section{ECLAMPSIA AND LUMBAR PUNCTURE}

\section{J. W. SNYDER, M.D. \\ MICHIGAN CITY, IND.}

At 1 a. m., April 23, 1917, I was called seven miles from town to see Mrs. W., aged 25 , with her first child. Pains had begun at $4 \mathrm{p}$. $\mathrm{m}$. the preceding afternoon, and at 11:30 she had a convulsion. By the time $I$ reached her she had had four convulsions, and a fifth quickly followed. In the intervals she was delirious, tossing about the bed. Restraint was necessary to keep her on the bed at all. On hasty examination I found the cervix dilated and the head in left occipito-anterior presentation on the perineum; but the patient seemed to be unable to deliver the child, mainly because she made no intelligent effort to aid the labor pains. Being alone, except for the assistance of an excited husband and a grandmother who could not speak English, I gave the patient ether and made a forceps delivery. When the patient recovered I gave her $1 / 2$ grain of morphin, and as the convulsions were returning I ordered her removal to the city

- hospital, to which she was admitted at $4: 30$ a. m. On catheterization, 4 ounces of urine were obtained which tested over one-half albumin by volume, and also gave a decided reaction for diacetic acid. One thousand c.c. of physiologic sodium chlorid solution were given under the breast, followed in two hours by 1,000 c.c. of sterile water. Sodium bicarbonate and glucose solution were given by bowel. One-fourth grain of morphin and $1 / 200$ grain of scopolamin were administered by hypodermic injection and repeated in two hours. Two minims of croton oil were given on the tongue.

Four hours after admission, the temperature was 102, the puise 108 and the respirations 34. Six convulsions had occurred in the four hours' time. In the next two hours there were four convulsions more severe than those that had occurred before. The temperature went up to 105.2 by axilla, the pulse was 130 , and the respirations were 36 . One three-hundredth grain of scopolamin and $1 / 6$ grain of morphin were given, and in the next hour three more convulsions occurred. At 11 o'clock the temperature was 106 by axilla, the reanirations 34 and the pulse 140 , very weak and irregular. The breathing was shallow and irregular, with considerable edema at the base of the lungs. The face was congested and cyanotic. As a last resort I did a spinal tap, not expecting any good, as I thought the patient would be dead inside of an hour. The spinal fluid did not seem to be under much increase of pressure, flowing slowly in drops and being perfectly clear. About 2 drams were removed and no more because I could see no reason to expect benefit from it. Before I left the room the appearance of the patient had changed. The face began to lose much of the congested appearance, and the respirations became more regular and deeper. Within one hour the temperature had fallen to 105 , the respirations were 34 , and the pulse was 112 . No more convulsions occurred. At $2 \mathrm{p}$. $\mathrm{m}$. the temperature was 103 , the pulse 108 , and the respirations 30 , and 26 ounces of urine were removed by catheter.

From that time on the patient made a steady recovery. The temperature reached normal on the third day, and the patient recovered consciousness on the evening of that day. She had no recollection of labor or anything following. Sodium bicarbonate and glucose solution was continued by bowel for several days, and the bowels were thoroughly evacuated. The patient left the hospital, May 5, in good condition except for some necrosis at the point of giving hypodermoclysis.
This case may be only an accident, but I believe that in similar cases the procedure merits repetition. It is, of course, not a measure to remedy the toxemia, but only a means to control the convulsions. I have found a report by $\mathrm{W}$. T. Wilson ${ }^{1}$ regarding this procedure in two cases of eclampsia with beneficial results. Recently Musser and Hufford ${ }^{2}$ reported a series in which lumbar puncture controlled the delirium of pneumonia. I believe the procedure is used also with advantage in the delirium of alcoholism and to control convulsions in meningitis.

\section{THE TREATMENT OF EPIDEMIC POL- IOMYELITIS WITH IMMUNE HORSE SERUM *}

\section{PRELIMINARY REPORT}

\section{E. C. ROSENOW, M.D. ROCHESTER, MINN.}

In a previous report, ${ }^{1}$ it has been shown that the serum of a horse, which had been immunized with streptococci isolated from the central nervous system of monkeys paralyzed with virus, had the power to neutralize virus in vitro, and to prevent poliomyelitis in monkeys following intracerebral inoculation of active virus. Moreover, this serum appeared to have a curative effect in the experimental disease in monkeys after the symptoms had begun.

Opportunity to test the effect of this serum in patients presented itself during the present epidemic of anterior poliomyelitis at Davenport, Iowa, and surrounding community. The routine procedure consists of making a spinal puncture for diagnostic tests and for relief of abnormal intraspinal pressure, and of injecting the serum. From 5 to 30 c.c. of spinal fluid are allowed to escape, depending on the age of the patient and the amount of pressure. The fluid is marle to flow slowly because it is believed that rapid withdrawal might be harmful. The cell count and Noguchi's globulin test are made at the bedside, and if positive, the injection of serum is given at once. The serum is activated with complement by adding one part of fresh guinea-pig serum to nine parts of the immune serum and incubating at 37 degrees for one hour. It is then diluted with equal parts of 0.85 per cent. salt solution. The diluted serum is injected slowly into a suitable superficial vein not later than thirty-six hours after activation. Approximately 2 c.c. of the mixture are injected per minute of time. The dose is varied according to the age of the patient and severity of the symptoms. Babies from about 1 to 2 years of age are given from 3 to 7 c.c. of serum at each injection, that is, 6 to 14 c.c. of the mixture; children from 2 to 5 years of age from 7 to 10 c.c., and older individuals from 10 to 20 c.c. The injections are repeated in from eight to twenty-four hours if necessary.

Every patient in whom the diagnosis is definite, and the disease still active, is given injections of serum irrespective of the severity of symptoms. Altogether forty-four patients have been treated. Of these nine died, a mortality of 20 per cent. Of the nine fatal

\footnotetext{
1. Wilson, W. T.: Lumbar Puncture for the Relief of Convulsions in Puerperal Eclampsia, THE Jouknal A. M. A., Sept. 2, 1916, p. 742. the Relief of Delirium in Lobar Pneumonia, The Jovrnal A. M. A. April 28, 1917, p. 1231 .

* From the Mayo Foundation.
1. Rosenow, E. C.: The Production of an Antipoliomyelitis Serum
} in Horses, The Journal A. M. A., July 28, 1917, p. 261. 